\title{
SABERES SOBRE BRINCAR: O QUE AS PESQUISAS PUBLICADAS NA ANPED REVELAM?
}

\author{
Tatiana Aparecida de MATTOS ${ }^{1}$ \\ Aline SOMMERHALDER ${ }^{2}$
}

RESUMO: Esse texto é decorrente de uma pesquisa de conclusão de Pós Graduação Lato Sensu em Educação Infantil, de uma universidade pública brasileira que investigou como o brincar se apresenta nas pesquisas produzidas no campo da Educação Infantil, publicadas nas Reuniões Anuais da ANPEd - Associação Nacional de Pós-Graduação e Pesquisa em Educação, em específico no Grupo de Trabalho 07: Educação das Crianças de 0 a 6 anos. Foram analisados artigos publicados no GT 07 das Reuniões Anuais de 2005 a 2011 dessa Associação, que abordaram o Brincar no cotidiano da Educação Infantil. Os resultados evidenciaram, dentre outros aspectos, que nas recentes publicações o brincar deve se apresentar como eixo central das práticas pedagógicas na Educação Infantil. Destaca ainda na análise destas produções as relações estabelecidas do brincar com outros fenômenos diretamente relacionados aos processos educativos das crianças na Educação Infantil, como: formação de grupo de crianças, consumo e cultura midiática.

PALAVRAS-CHAVE: Brincar. Práticas pedagógicas. Educação infantil. Crianças.

\section{Introdução}

Das experiências com a docência na educação infantil, em diversos projetos de formação de professores e na produção de pesquisas nesse campo (SOMMERHALDER; ALVES, 2011; SOMMERHALDER; OLIVEIRA; ALVES, 2011) indica-se que na atualidade, de forma geral, as práticas pedagógicas assumem o brincar como uma atividade que, muitas vezes, se faz presente de forma cindida das ações de cuidar e educar da criança na Educação Infantil. Percebe-se que muitas práticas cotidianas ainda revelam o controle e a restrição, por parte dos adultos, dos tempos e espaços para brincar e preocupação exacerbada pelo ensino e a aprendizagem que intenciona a preparação da criança para a escolarização do ensino fundamental $\left(1^{\circ}\right.$ aos 5 anos). Brincar se distancia da compreensão de eixo integrador das linguagens curriculares e princípio norteador das propostas pedagógicas das instituições de educação infantil.

\footnotetext{
${ }^{1}$ Professora de Educação Infantil da rede municipal de ensino. São Carlos - SP -Brasil. 13565-905 tatimattos22@ig.com.br.

${ }^{2}$ Docente do Programa de Pós-Graduação em Educação. UFSCar - Universidade Federal de São Carlos. Departamento de Teorias e Práticas Pedagógicas. São Carlos - SP - Brasil. 13565-905 sommeraline@hotmail.com.
} 
O presente estudo teve como questão de pesquisa: o que as pesquisas publicadas na Anped abordam sobre o brincar na educação infantil? Teve por objetivo investigar, por meio de recentes pesquisas científicas publicadas, como o brincar se apresenta no cotidiano da Educação Infantil.

Brincar é compreendido neste estudo como elemento da cultura da infância, uma prática social e linguagem que favorece a integração das linguagens curriculares na Educação Infantil e no Ensino Fundamental, colaborando com as conquistas de desenvolvimento e os processos de aprendizagem das crianças.

Para Brougère (2002), a criança adquire, constrói sua cultura lúdica brincando. O autor revela que a cultura lúdica, como toda cultura, é produto das relações sociais entre as pessoas, como por exemplo, das experiências lúdicas que ocorrem nas relações entre mãe e bebê. Brincar é uma aprendizagem que ocorre na relação das crianças com outras pessoas e com os objetos, ou seja, com a cultura que a rodeia.

Considera-se ainda que ao brincar, a criança vivencia uma diversidade de experiências indispensáveis para a garantia de efetivas aprendizagens favoráveis ao seu desenvolvimento. Reconhecemos então o lúdico (brincadeiras, brinquedos e jogos) como uma linguagem; uma atividade intensiva da criança, peculiar à sua cultura, às suas necessidades e seus interesses.

Em nossa compreensão, brincar é a forma para a superação de práticas pedagógicas escolarizantes e cindidas em relação ao educar e cuidar na Educação Infantil. Brincar da criança não é apenas um ato espontâneo de um determinado momento, pois cada criança frente ao jogo apresenta sua própria história (SOMMERHALDER; ALVES, 2011).

As Diretrizes Curriculares Nacionais para a Educação Infantil - DCNEI (BRASIL, 2010) afirmam que a responsabilidade social e a função política das creches e pré-escolas se efetivam com a garantia do direito a uma educação de qualidade comprometida com o cuidado; o desenvolvimento; a cidadania e o bem-estar das crianças e de suas famílias. Apresentam o brincar como princípio integrador das propostas pedagógicas e curriculares da Educação Infantil e mostram a importância da Educação Infantil para o pleno desenvolvimento das crianças, assim como a excelência do brincar e do interagir na sua formação. 


\section{Percurso metodológico}

Realizou-se uma pesquisa de abordagem qualitativa com etapa bibliográfica (MIOTO; LIMA, 2007) e documental (LÜDKE; ANDRÉ, 1986), esta última contemplando as produções científicas publicadas nas Reuniões da Associação Nacional de Pós-Graduação e Pesquisa em Educação (Brasil), conhecida como ANPEd ${ }^{3}$ e pelo seu Grupo de Trabalho (GT) 07: Educação de Crianças de 0 a 6 anos. Justifica-se a escolha do estudo das produções das Reuniões Anuais da ANPEd - GT 07 em razão do reconhecimento científico que essa Associação tem no campo da educação.

Foi realizado um levantamento das produções atuais da ANPEd, em que foram investigados artigos publicados em forma de Trabalhos e Pôsteres no GT 07 das Reuniões Anuais de 2005 a 2011, que tiveram como foco de pesquisa o brincar no cotidiano da Educação Infantil. Para isso, foi visitado o site da ANPEd para acesso aos trabalhos científicos e pôsteres publicados na íntegra nas Reuniões realizadas no período selecionado. Delimitou-se a análise de 05 produções na íntegra, sendo 04 trabalhos e 01 pôster, publicados no período de 2005 a 2011 tomando como critério para essa seleção as publicações que diretamente abordaram a temática do brincar na educação das crianças de 0 a 6 anos. Vale destacar que não foram encontradas publicações de trabalhos relacionados diretamente à temática do brincar, nos anos de 2008 e 2009.

A análise foi realizada qualitativamente considerando a literatura escolhida e os objetivos da pesquisa. As pesquisas escolhidas foram analisadas a partir dos seguintes aspectos de análise: 1) Objetivos e intencionalidades das pesquisas produzidas, 2) Contexto em que a pesquisa foi realizada; 3) Principais resultados e contribuições que estas pesquisas trazem para o campo da temática do brincar no cotidiano da Educação Infantil.

\section{Resultados e discussão}

Em relação ao primeiro aspecto de análise: Objetivos e intencionalidades das pesquisas produzidas, no ano de 2005, a ANPEd publicou o trabalho "Educação Infantil, gênero e brincadeiras: das naturalidades às transgressões", de autoria de Finco.

\footnotetext{
${ }^{3}$ A ANPEd é uma sociedade brasileira civil fundada em 1976 pelos Programas de Pós-Graduação do Brasil, da Área de Educação.
} 
Este trabalho traz os resultados finais da pesquisa de mestrado da autora. O objetivo principal da pesquisa foi observar as brincadeiras de meninos e meninas da Educação Infantil, analisando o modo como se relacionavam e se manifestavam culturalmente frente às questões/relações de gênero (FINCO, 2005).

A pesquisa "As culturas da infância nos espaços-tempos do brincar: estratégias de participação e construção da ordem social em um grupo de crianças de 4 a 6 anos", publicado na ANPEd de 2006, produzido por Borba resulta da tese de doutorado da autora. Borba (2006) focalizou tanto o brincar quanto as relações sociais entre as crianças nos momentos de brincadeiras, buscando compreendê-los ao mesmo tempo nas relações que estabelecem entre si e na constituição das culturas da infância. O objetivo central da pesquisa foi compreender como as crianças, nas relações que estabelecem entre si e nas formas de ação social que constroem nos espaços-tempos do brincar, constituem suas culturas da infância e são também por elas constituídas.

O pôster "O brincar no cotidiano escolar da Educação Infantil: criar e recriar de cultura e de aprendizado", publicado na ANPEd de 2007, de autoria de Trevisan é parte da dissertação de mestrado da autora. Segundo Trevisan (2007) sua intenção foi compreender como o brincar acontece na Educação Infantil, ou seja, como ele se apresenta no cotidiano dos sujeitos escolares e como foi se colocando e sendo problematizado no decorrer das mudanças na sociedade.

A pesquisa de Salgado (2010) “'Pares ou Ímpares?”: consumo e relações de amizade entre as crianças na formação de grupos para brincar”, publicado na ANPEd 2010, é produto da tese de doutorado da autora. O principal objetivo da pesquisa foi compreender os modos como as crianças, em meio às referências simbólicas da cultura midiática, se organizam socialmente e produzem culturas lúdicas específicas, trazendo à tona valores, saberes e aprendizagens que traduzem os significados que conferem à vida fora do espaço escolar.

A publicação de 2011 intitulada "A construção da cultura de pares no contexto da Educação Infantil: brincar, ler e escrever", de autoria de Neves analisa o contexto de brincadeiras de um grupo de crianças de 4 a 5 anos da Educação Infantil, a partir do olhar para as interações estabelecidas entre elas e a construção de grupos para brincar e aprender, em especial a aquisição da leitura e escrita.

No segundo aspecto: Contexto em que a pesquisa foi realizada, a autora Finco (2005) utilizou de uma variedade de procedimentos e instrumentos metodológicos: registro fotográfico, registro em caderno de campo, utilização da produção 
cinematográfica, utilização de imagens de obras de arte, literatura infantil, que, segundo ela, relacionadas entre si possibilitaram uma análise diferenciada sobre seu objeto da pesquisa: as questões de gênero manifestadas nas brincadeiras das crianças da Educação Infantil.

Borba (2006) realizou sua pesquisa em uma escola municipal de Educação Infantil situada em Niterói, Rio de Janeiro com um grupo de crianças de 4 a 6 anos, nos espaços do brincar. A autora focalizou a questão da participação e da ordem social no grupo de pares, através do olhar sobre o acesso das crianças às brincadeiras, discutindo as estratégias de entrada e resistência das crianças nos grupos e os aspectos que estas revelam sobre as relações sociais. A pesquisa teve um caráter etnográfico e acompanhou um grupo de crianças durante suas atividades de brincadeiras livres. A partir da observação participante, a autora acompanhou as atividades buscando adentrar nos mundos sociais e culturais das crianças. As crianças foram observadas em situações naturais e rotineiras do cotidiano escolar da Educação Infantil, em suas ações desenvolvidas nos espaços destinados ao brincar, especialmente dois parques e uma casa de alvenaria mobiliada com materiais proporcionais ao tamanho das crianças. Foram utilizadas videogravações, audiogravações e comentários escritos em notas de campo, além de entrevistas e conversas informais com as crianças.

Trevisan (2007) focalizou o brincar da criança no cotidiano de uma escola de Educação Infantil da rede municipal de Santo Ângelo, Rio Grande do Sul. Trata-se de uma pesquisa de mestrado que estava em andamento no ano de 2007. Como o texto publicado resultou da pesquisa em andamento, a autora não apresenta informações sobre procedimentos de coleta de dados e os sujeitos participantes do estudo.

Salgado (2010) investigou o cotidiano das crianças em duas instituições de Educação Infantil, sendo uma turma de crianças entre 4 e 5 anos, de uma unidade de Educação Infantil da rede pública do município de Rondonópolis, Mato Grosso e uma turma de Educação Infantil, com crianças de 5 a 6 anos, em uma das unidades do Serviço Social e do Comércio - SESC, na cidade do Rio de Janeiro.

Neves (2011) realizou uma pesquisa de abordagem etnográfica interacional em uma escola municipal de Educação Infantil em Belo Horizonte, estado de Minas Gerais. A autora analisou as atividades diárias desenvolvidas numa turma de 21 crianças (10 meninas e 11 meninos) de 4 a 5 anos, com o objetivo de entender o que significa a brincadeira para o grupo pesquisado e, mais especificamente, quanto tempo é destinado ao brincar na rotina diária da turma pesquisada. A autora relata em seu trabalho que a 
construção dos dados para a pesquisa deu-se por meio de observação participante, conversas e entrevistas com as crianças e anotações em diário de campo.

Como terceiro elemento de análise: Principais resultados e contribuições que estas pesquisas trazem para o campo da temática do brincar no cotidiano da Educação Infantil, a pesquisa de Finco (2005) mostra como as hierarquias de gênero são contestadas e mantidas por meninos e meninas que vivem em um ambiente coletivo e público de educação. Mostra como meninos e meninas de 4 a 6 anos de uma pré-escola, vêm participando das transformações em nossa sociedade, como portadores de história, como atores dos processos sociais, reproduzindo a cultura.

Segundo Finco, a pesquisa se defrontou com as dificuldades em trabalhar com as questões de gênero na infância, que se traduz na carência de pesquisas sobre o tema. Segundo a autora, “[...] na área da educação de crianças de 0 a 6 anos, ainda se verifica a escassez de pesquisas que articulam gênero, relações entre crianças e práticas educacionais" (FINCO, 2005, p.4).

Finco (2005) relata que no contexto observado foi possível verificar que os meninos gostam de brincar de casinha, com boneca, de salão de beleza e as meninas gostam de subir em árvores, jogar futebol e brincar com espada e carrinho. Para esta autora, a variedade dos brinquedos e as diversas opções de brincadeiras favorecem para que todos os espaços sejam ocupados por meninas e meninas indiscriminadamente. As crianças brincam espontaneamente com os brinquedos que escolhem, sem constrangimentos de gênero.

Finco (2005) afirma que meninos e meninas movimentam, circulam e se agrupam de diferentes formas para brincar. Relata que foi possível considerar que os estereótipos dos papéis sexuais, os comportamentos pré-determinados, os preconceitos e discriminações são construções culturais, que existem nas relações dos adultos, mas ainda não conseguiram influenciar totalmente a cultura da criança. São os adultos que demandam que meninas sejam de um jeito e que os meninos tenham outros comportamentos. As relações ocorridas na escola pesquisada podem ser consideradas momentos importantes para se construir uma relação não hierárquica, uma relação de respeito entre os gêneros.

A pesquisa revela ainda que em relação ao uso dos brinquedos foi possível compreender a positividade das transgressões, nos momentos de brincadeiras, percebendo como meninos e meninas resistem aos padrões pré-estabelecidos, transgridem os padrões considerados "certos" e "errados", recriando e inventando novas 
formas de brincar, novas formas de ser. As categorizações dos brinquedos em masculino e feminino são construções criadas por adultos e não tem significado para as crianças nos momentos das brincadeiras.

Dentre as contribuições deixadas pela pesquisa destaca-se a necessidade de desconstrução da lógica binária na apresentação do mundo para as crianças, uma vez que enquanto os brinquedos e brincadeiras estiverem sendo associados a significados masculinos e femininos, que hierarquizam coisas e pessoas, realiza-se uma apresentação de mundo excludente.

Borba (2006) ao trazer as contribuições de seu trabalho sobre as estratégias de participação e construção da ordem social em grupos de crianças brincando, afirma que na maioria das vezes, as crianças usam mais de uma estratégia (simples aproximação no espaço da brincadeira em curso; contribuir com algum brinquedo ou objeto - dando ou trocando; solicitar ou declarar diretamente a participação) para conseguirem participar de uma brincadeira, ajustando as formas de entrada aos tipos de brincadeira, aos grupos, às interações em curso e às respostas de aceitação ou de resistência às suas tentativas.

De acordo com Borba (2006) ainda que durante as brincadeiras tenha sobressaído o investimento das crianças na negociação de conflitos para garantir o processo interativo do brincar, também se revelaram hierarquias e relações de poder entre elas, as quais lhes conferem autoridade para definir quem pode ou não participar de determinadas brincadeiras.

A pesquisa de Trevisan (2007) afirma que na atualidade, passamos por um processo de interesse a serviço do consumo e que o mercado de brinquedos foi sendo ampliado na medida em que os espaços físicos para brincar foram sendo diminuídos.

Para a autora, as crianças têm trazido para os seus "mundos de faz-de-conta" elementos da cultura da mídia, o que não quer dizer que elas tenham deixado de lado brincadeiras passadas como: cantigas de roda, brincar de casinha, de caçador etc. dentre as contribuições da investigação destaca-se que os/as educadores/as infantis precisam aproximar da realidade infantil, da cultura infantil.

A pesquisa de Salgado (2010) possibilita afirmar que o consumo e as relações de amizade constituíram-se, em ambos os contextos, como estratégias significativas para a formação de grupos e para neles se inserir como meio de participar das brincadeiras que acontecem nas instituições educativas. Especificamente no tocante ao consumo, aponta que determinados objetos e informações que circulam na mídia, transformam-se em 
verdadeiros passaportes de entrada das crianças nas brincadeiras e nos grupos de pares, demarcando territórios e definindo quem pode ou não brincar.

Aponta, ainda, que, nos grupos de crianças por ela pesquisados, os objetos revelaram relações de poder. Conferindo status àqueles que os consomem, passam a ser lances importantes, no jogo e na vida, para assumir liderança e superar o outro. Estes objetos tornaram-se elementos necessários para se estabelecer uma relação entre os grupos de crianças e edificar uma ponte entre aquele que queria participar e aquele que assumia o poder no grupo da brincadeira. E destaca que a brincadeira da criança não se caracteriza exclusivamente pela emergência do prazer, mas se define, principalmente, como território de conflitos, de barganhas e negociações.

A pesquisa de Neves (2011) mostrou que a professora observada tinha como principal objetivo do trabalho pedagógico centrar-se no desenvolvimento das habilidades de socialização das crianças, tais como autonomia, negociação de conflitos, ajuda mútua e construção da história do grupo. Uma desses momentos pedagógicos foi a construção da roda que se apresentou como uma rotina cultural da turma, reafirmando o pertencimento dos membros ao grupo ao dar visibilidade às suas ações, falas, relações de amizade e suas atividades ao longo dos dias, ficando evidente a liberdade de movimento e de participação das crianças em diversos momentos do cotidiano institucional.

A pesquisa concluiu que é possível a construção de uma prática pedagógica que respeite as culturas de pares e o desenvolvimento infantil, integrando o brincar e a construção do conhecimento, em direção a um "brincar letrando" ou a um "letrar brincando" na Educação Infantil e nos anos iniciais do Ensino Fundamental.

Percebemos que todas as pesquisas tiveram o mesmo espaço de produção: instituições de Educação Infantil, portanto, todas abordaram o brincar no cotidiano de instituições destinadas à educação de crianças pequenas. Todas tiveram como participantes crianças brincando e não adultos falando sobre esta linguagem privilegiada da infância. Nenhuma produção mostrou o olhar "adultocêntrico" para o brincar da criança na Educação Infantil.

Um fato que se fez notável nas produções de Borba, Salgado e Neves, refere-se ao grupo idade das crianças que participaram da investigação, ou seja, todas entre 4 e 6 anos. Este estudo permitiu revelar a ausência de pesquisas publicadas, nessa fonte de dados, sobre o brincar das crianças de 0 a 3 anos na Educação Infantil, neste período investigado. 
O brincar de crianças no cotidiano da Educação Infantil foi o foco de olhar em todas essas investigações, embora cada uma tenha apresentado intencionalidades diferentes para este olhar, enfatizando, assim, aspectos específicos como: gênero, formação de grupo de pares no contexto das brincadeiras, relações de amizade, relações entre o lúdico e a construção de conhecimento e influência do consumo e da cultura midiática nas brincadeiras das crianças.

O discurso referente ao valor do brincar na infância e, em específico, na Educação Infantil, permeou todos os trabalhos. Nestes, o brincar vem sendo apontado como a principal linguagem que as crianças usam tanto para se apropriarem do mundo quanto para se expressarem.

Ao se pensar a criança em todas as suas dimensões, os estudos em questão demonstraram encontrar na brincadeira a principal forma de expressão das crianças: a forma como a criança se manifesta culturalmente. Brincar ofereceu a estes pesquisadores múltiplas possibilidades de investigação a partir da própria produção cultural infantil e das condições em que isso ocorre.

Conceitualmente, esses estudos revelam que brincar é uma atividade social significativa que pertence à dimensão humana e constitui para as crianças como uma forma de ação social para a construção das suas relações sociais e das formas coletivas e individuais de interpretarem o mundo. Nestas pesquisas, brincar foi apontado como a forma privilegiada de participação das crianças na cultura. Todos estes estudos consideraram que as crianças produzem algo novo ao brincar (são produtoras de cultura) e que devem ser vistas e compreendidas como seres ativos, situados no tempo e no espaço, participantes e atores na relação com si próprios, como os outros e com o mundo.

Estas pesquisas mostraram-se valiosas em relação às significativas contribuições que trouxeram para o campo da Educação Infantil, em especial para o tema ludicidade. Foi possível ainda verificar que a imersão na principal linguagem da infância - que é o brincar - permitiu a todos os pesquisadores a investigação de outros fenômenos diretamente voltados às crianças no cotidiano da Educação Infantil, como: questões de gênero, formação de grupo de pares, relações de amizade, consumo e cultura midiática. Percebemos que brincar é o eixo central que atravessou todos estes trabalhos analisados e que permitiu investigar, por meio dele, também outros fenômenos. 


\section{Considerações finais}

Sabemos que brincar é pouco vivenciado pelas crianças na Educação Infantil, em razão da ênfase na quantidade e tempo destinados às tarefas/atividades a serem realizadas dentro das salas. Em nossa compreensão, o lúdico/brincar é a forma para a superação de práticas pedagógicas escolarizantes e cindidas em relação ao educar e cuidar na Educação Infantil.

Em todos estes trabalhos brincar foi compreendido como uma linguagem privilegiada da criança, entendido enquanto elemento lúdico e pertencente à cultura da infância. Todos os pesquisadores partiram da idéia de que, ao brincar a criança vivencia uma diversidade de experiências indispensáveis para a garantia de efetivas aprendizagens favoráveis ao desenvolvimento infantil. Reconheceram no lúdico (brincadeiras e jogos) um comportamento próprio da criança e destacaram seu inquestionável valor formativo e educativo.

Ao se proporem, portanto, a investigar fenômenos relativos à infância, todos os pesquisadores optaram por escutar as vozes das crianças brincando na Educação Infantil, ao invés de buscar as vozes dos adultos falando sobre a criança e o brincar na infância. Somado a isso, nas pesquisas em questão foi possível verificar que não se fez presente uma perspectiva teórica única, mas sim uma multiplicidade de autores e literaturas.

É preciso fortalecer práticas pedagógicas que integrem o brincar e a construção dos conhecimentos tanto na Educação Infantil, quanto nos anos iniciais do Ensino Fundamental. Um caminho é a construção coletiva de projetos pedagógicos que articulem as experiências e saberes das crianças às práticas docentes, realizando no cotidiano das escolas um 'fazer pedagógico brincante, marcado pela sensibilidade e amorosidade pela criança.

\section{KNOWLEDGE ABOUT PLAY: WHAT RESEARCH PUBLISHED IN ANPED REVEAL?}

ABSTRACT: This text is the result of a survey completed Postgraduate Sensu Lato in Early Childhood Education, a Brazilian public university that investigated how the play presents the research conducted in the field of Early Childhood Education, published in the Annual Meetings of ANPEd - National Association of Post Graduation and Research in Education, in particular the Working Group 07: Education of Children 0-6 
years. We analyzed articles published in the Annual Meetings of the GT 07. The results showed, among other things, that in recent publications the play should be presented as the centerpiece of pedagogical practices in Early Childhood Education. It also emphasizes the analysis of the relationships established productions of playing with other phenomena directly related to the educational process of children in kindergarten, such as group training of children, consumer and media culture.

KEYWORDS: Play. Pedagogical practice. Early childhood education. Children.

\section{REFERÊNCIAS}

BRASIL. Ministério da Educação. Secretaria de Educação Básica. Diretrizes Curriculares Nacionais para a Educação Infantil. Brasília: MEC, SEB, 2010. Disponível em:

<http://portal.mec.gov.br/index.php?option=com_docman\&task=doc_download\&gid=9 769\&Itemid>. Acesso em: 29 mai. 2014.

BORBA, A. M. As culturas da infância nos espaços-tempos do brincar: estratégias de participação e construção da ordem social em um grupo de crianças de 4-6 anos. In: REUNIÃO ANUAL DA ANPED, 29., 2006, Caxambu, MG. Anais... Caxambu, MG: ANPEd, 2006.

BROUGÈRE, G. A criança e a cultura lúdica. In: KISHIMOTO, T. M. (Org.). O Brincar e suas teorias. São Paulo: Pioneira Thompson, 2002. p.19-32.

FINCO, D. Educação infantil, gênero e brincadeiras: das naturalidades às transgressões. In: REUNIÃO ANUAL DA ANPED, 28., 2005, Caxambu, MG. Anais... Caxambu, MG: ANPEd, 2005.

LÜDKE, M.; ANDRÉ, M. E. D. A. Pesquisa em educação: abordagens qualitativas. São Paulo: E.P.U., 1986.

MIOTO, R. C. T.; LIMA, T. C. S. Procedimentos metodológicos na construção do conhecimento científico: a pesquisa bibliográfica. Revista Katál, Florianópolis, v.10, p.37-45, fev. 2007.

NEVES, V. F. A. A construção da cultura de pares no contexto da Educação Infantil: brincar, ler e escrever. In: REUNIÃO ANUAL DA ANPED, 34., 2011, Natal, RN. Anais... Natal, RN: ANPEd, 2011.

SALGADO, R. G. "Pares ou Ímpares?": consumo e relações de amizade entre as crianças na formação de grupos para brincar. In: REUNIÃO ANUAL DA ANPED, 33., 2010, Caxambu, MG. Anais... Caxambu, MG: ANPEd, 2010.

SOMMERHALDER, A.; ALVES, F. D. Jogo e a educação da infância: muito prazer em aprender. Curitiba: Editora CRV, 2011. 
SOMMERHALDER, A.; OLIVEIRA, M. L. ; ALVES, F. D. O lúdico e educação escolarizada da criança: implicações para a prática pedagógica. Doxa: Revista Brasileira de Psicologia e Educação, v.15, n.1, p.33-44, 2011.

TREVISAN, R. P. O brincar no cotidiano escolar da Educação Infantil: criar e recriar de cultura e de aprendizado. In: REUNIÃO ANUAL DA ANPED, 30., 2007, Caxambu, MG. Anais... Caxambu, MG: ANPEd, 2007. 